\title{
Facial Clinimetric Evaluation Scale and Synkinesis Assessment Questionnaire Translation into Brazilian Portuguese: A Validation Study
}

Joana Tavares-Brito ${ }^{1,2}$ Anna Carolina de Oliveira Fonseca ${ }^{3}$ Rodolfo Prado Torres ${ }^{20}$

Martinus M. van Veen ${ }^{1,4}$ Jacqueline Greene ${ }^{1} \quad$ Raquel Salomone $^{3} \quad$ Fayez Bahmad Jr $^{20}$ Tessa Hadlock ${ }^{1}$ Ricardo Ferreira Bento ${ }^{3}$

\footnotetext{
${ }^{1}$ Department of Otolaryngology, Facial Nerve Center, Massachusetts Eye and Ear Infirmary and Harvard Medical School, Boston, Massachusetts, United States

2 Faculty of Medicine, Universidade de Brasília, Brasília, Distrito Federal, Brazil

${ }^{3}$ Department of Otolaryngology, Universidade de São Paulo, Faculdade de Medicina, São Paulo, SP, Brazil

${ }^{4}$ Department of Plastic Surgery, University Medical Center Groningen and University of Groningen, Groningen, The Netherlands
}

Address for correspondence Rodolfo Prado Torres, Faculdade de Medicina, Universidade de Brasília, Campus Universitário Darcy Ribeiro, Asa Norte, Brasília, DF, 70910-900, Brazil (e-mail: rodf_t@icloud.com).

Int Arch Otorhinolaryngol 2020;24:e24-e30.

\begin{abstract}
Introduction Facial nerve palsy results in both functional disability and psychological morbidity. There are several well-established grading scales to quantify the quality of life of these patients.

Objective Translate and validate the Facial Clinimetric Evaluation (FaCE) scale and Synkinesis Assessment Questionnaire (SAQ) to Brazilian Portuguese.

Methods This study adopted a forward-backward translation method and performed cross-cultural adaptation. A pilot study was conducted to correct any confusing language and to evaluate content validity. A validation study was then performed. Internal consistency of the Brazilian Portuguese version of the FaCE and SAQ items was evaluated by Cronbach's alpha coefficient. Construct validity was assessed by Spearman's Rank Correlation Coefficient between FaCE and SAQ scores to eFACE, HouseBrackmann, Short Form 12 (SF-12) and Facial Disability Index (FDI) (sub)scores.

Results A total of 90 patients were included. Cronbach's alpha for total domain scored 0.881 for FaCE and 0.809 for SAQ. FaCE total score correlation to eFACE total and HouseBrackmann showed Spearman's r value of 0.537 and -0.538 , respectively $(p<0.001)$. SAQ correlation to eFACE synkinesis subdomain was $-0.449(p<0.001)$. No correlation was

Keywords

- facial palsy

- synkinesis

- translation

- validation

- quality of life

- questionnaire found between SAQ and HB score. FaCE total score correlations were of 0.301 and 0.547 for SF-12 PCS and MCS, respectively $(p<0.001)$. Correlation between FaCE total and FDI Physical and Social/well-being functions were 0.498 and $0.567(p<0.001)$.

Conclusion Brazilian Portuguese FaCE scale and SAQ versions achieved high validity and reliability in the present study. These translated instruments demonstrated good psychometric properties, being proper to use in clinical practice in Brazil and with Brazilian Portuguese speakers.
\end{abstract}

received

February 27, 2019

accepted

August 1, 2019
DOI https://doi.org/

10.1055/s-0039-1697992.

ISSN 1809-9777.
Copyright $\odot 2020$ by Thieme Revinter

Publicações Ltda, Rio de Janeiro, Brazil
License terms

(c) (i) $\ominus$ (\$) 


\section{Introduction}

Facial palsy (FP) is a functional disability that can be disfiguring and devastating, ${ }^{1}$ and FP patients have an increased risk of depression, isolation and lower quality of life $(\mathrm{QoL}) .^{2-4}$

Multiple clinician-reported scales have been developed to quantify facial function and assess intervention results in cases of FP; however, these scales do not evaluate the psychosocial implications of FP from the patient perspective..$^{5-8}$

To fully evaluate patient-reported outcome measures and disease-specific QoL, self-reported instruments were developed and validated for the FP clinical practice. ${ }^{8-11}$ The Facial Clinimetric Evaluation instrument ( $\mathrm{FaCE}$ ) is a widely adopted patient-reported outcome measure of FP-related QoL, ${ }^{10}$ and the Synkinesis Assessment Questionnaire (SAQ) is an instrument specific for the self-assessment of synkinesis. ${ }^{11}$

The FaCE scale has already been translated and validated into Swedish, Dutch, German and Chinese, ${ }^{12-15}$ and the SAQ, to Dutch. ${ }^{16}$ The validation of QoL questionnaires in different languages involves rigorous translation methods. ${ }^{17,18}$ The forward-backward translation is the most commonly used method to translate QoL questionnaires, ${ }^{13}$ and cultural adaptation to the language must be performed to maintain internal validity. $^{18}$

\section{Objectives}

The present study aims to translate and cross-culturally adapt the FaCE scale and SAQ into Brazilian Portuguese, to assess construct validity and internal consistency, and to validate their use with the intent of developing accredited instruments for the clinical practice in Brazil, which will also benefit Brazilian Portuguese-speaking patients suffering from FP and synkinesis around the globe.

\section{Methods}

\section{Study Design}

The present study was designed and conducted in Brazil and in the United States. Formal approval of the institutional review board and ethics committee was obtained prior to the beginning of the study in both countries under the IRBNet ID 1203812 Protocol version v1/2.26.2018 and Project Analysis $\mathrm{n}^{\circ} 2003634$. Permission was given by the developers of the FaCE scale and SAQ to translate and validate their use into Brazilian Portuguese.

\section{Translation Method}

The present study adopted a forward-backward translation method and performed a cross-cultural adaptation as recommended by international QoL translation guidelines. ${ }^{9,19-21}$ Two Brazilian Portuguese native speakers ( $A^{*}$ and $B$ ) with proficient English as a second language, one being a medical doctor $\left(A^{*}\right)$, independently translated the original FaCE and SAQ into Brazilian Portuguese. These two versions were afterwards merged into a single version by a committee consisting of the authors of the present study. The merged version was independently back-translated into English by two American English native speakers with profi- cient Portuguese as their second language. These two versions were compared with the original FaCE scale and SAQ by the committee and again back-translated to Brazilian Portuguese by the former authors ( $A^{*}$ and $B$ ) into a final consensus version, which was approved by the committee for a pilot study. These four steps that comprise the forward-backward translation method are sequentially named forward-translation, reconciliation (merging), back-translation and pilot study. ${ }^{17}$ This process of forward-backward translation as used in the present study is illustrated in - Fig. 1. The Brazilian Portuguese versions compared with the original versions demonstrated no conceptual differences regarding the content and structure of the questions.

A pilot study was conducted to correct any confusing language in the translated versions of the questionnaires. The participants, who were native Brazilian Portuguese speakers, were asked to fill out the FaCE scale, the SAQ and a short questionnaire about the relevance, difficulty of the questions, and ease to understand the language used in the questionnaires. An electronic link was sent via e-mail for the participants to answer these questionnaires on the REDCap electronic data capture tools platform, ${ }^{22}$ after which they were personally contacted by phone or email regarding further commentaries.

\section{Validation}

The validation and reliability study were performed at an institutional FP center in the city of São Paulo, Brazil, between April 2018 and September 2018. The Promptly Health data platform was used to collect the patients' questionnaires. During the visit to the clinic, an assessment of facial function was made using the eFACE facial grading system ${ }^{7}$ and the House-Brackmann (HB) score. ${ }^{5}$ The patients were asked to fill out the Portuguese version of the FaCE scale, SAQ, Facial Disability Index (FDI) ${ }^{9}$ and the Short form 12 (SF-12), ${ }^{23}$ as well as an informed consent form. Patients younger than 18 years old, non-native Brazilian Portuguese speakers, and those without FP were excluded. This age-related exclusion criterion was deemed necessary to ensure the full comprehension of all of the questionnaires' items.

The FaCE scale (sub)scores and the SAQ total score were correlated to each other and to the eFACE, HB, FDI and SF-12, (sub)scores to analyze the construct validity of the Brazilian Portuguese versions of the FaCE scale and SAQ. Reliability was analyzed by internal consistency.

\section{Measurement Instruments}

The FaCE scale is an FP-related self-assessment QoL questionnaire comprising 15 questions based on a 5-point Likert-scale that evaluates the intensity and frequency of physical and psychosocial impairments in 6 domains of facial function: facial movement, facial comfort, eye comfort, oral function, lacrimal control and social function. Transformed total and domain scores are calculated on a scale that ranges from 0 (worst) to 100 (best). ${ }^{10}$

The SAQ is a nine-item patient-reported outcome measure of facial synkinesis severity. The answers are given using a fivepoint ordinal answer scale. The SAQ score can be calculated 


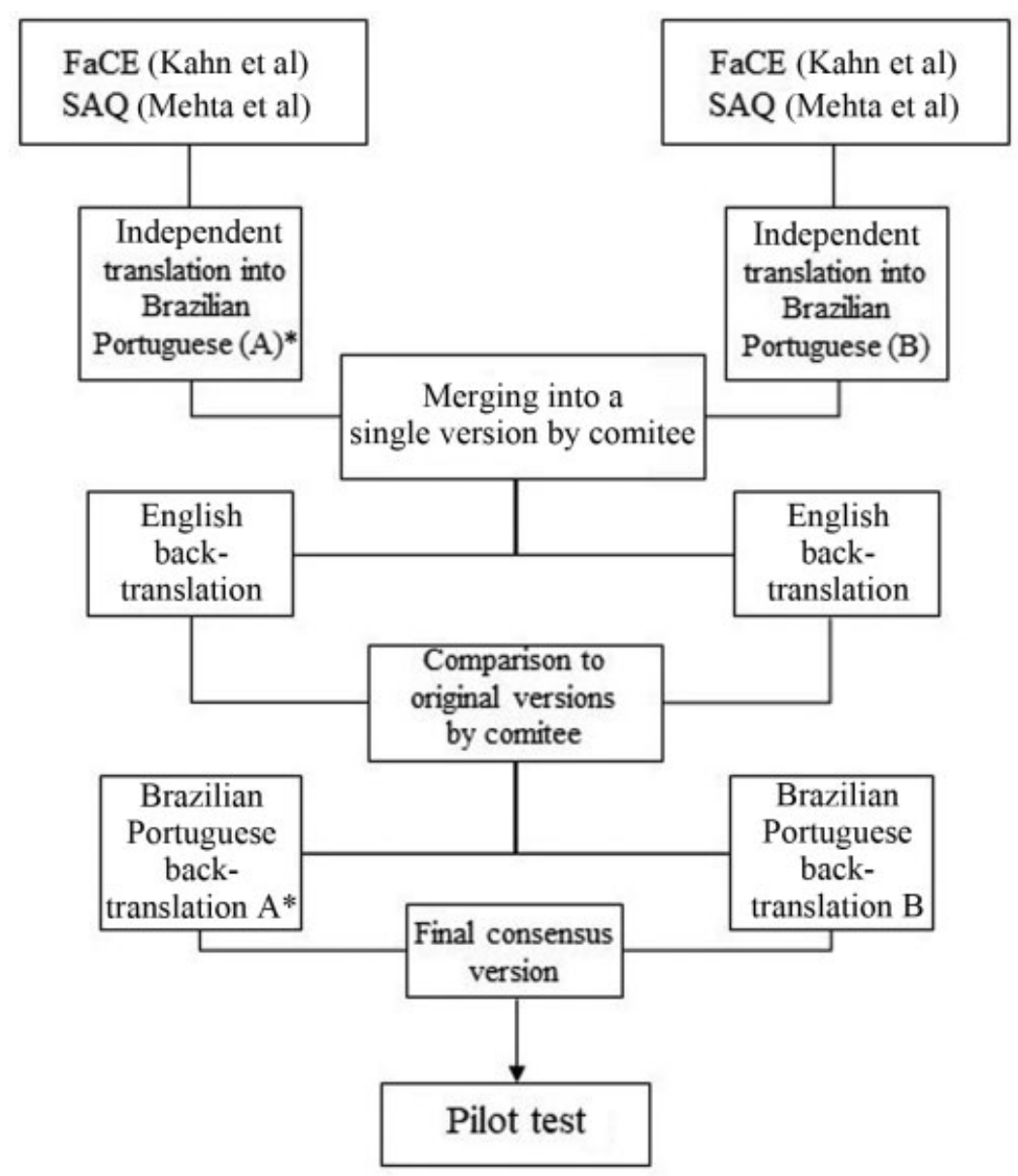

Fig. 1 Summarized forward-backward translation method in the present study. Translators A* and B are two native Brazilian speakers. The American English speakers who performed the back-translation were blinded to the original questionnaires. The committee was composed of the authors of the study. $\left({ }^{*}\right)$ Corresponds to a Medical Doctor.

ranging from 20 (best) to 100 (worst: severe synkinesis, all the time). ${ }^{11}$

The FDI is a ten-item FP-related QoL questionnaire. Two domain scores can be generated from this instrument: a physical function (FDI-P) and a social/well-being function (FDI-S). Both domain scores range from 0 (worst) to 100 (best). ${ }^{9}$ A Brazilian Portuguese version, though not yet validated, was used.

The SF-12 is a general health-related QoL questionnaire. It consists of 12 items based on which a physical health score (PCS) and a mental health score (MCS) can be calculated, ranging from 0 (worst) to 100 (best). ${ }^{13,24}$ The SF-12 was previously translated and validated for Brazilian Portuguese. ${ }^{23}$ Permission and license were obtained from QualityMetric Incorporated and Medical Outcomes Trust for version SF-12v2 to be used.

The degree of FP was estimated with the eFACE, an easyto-use clinical measure used by the attending physicians, and the $\mathrm{HB}$ score. In addition, information regarding etiology, duration, side affected and whether therapy was previously received was collected. Data was entered in the International Business Machines Statistical Package for the Social Sciences (IBM SPSS Statistics, IBM Corp., Armonk, NY, US) software, version 20.0 for the statistical analysis.

\section{Statistical Methods}

Descriptive statistics were provided using numbers and frequencies, means and standard deviations (SD), and medians and interquartile ranges (IQRs) when appropriate. Comparisons between groups were made using MannWhitney U tests. Correlations were analyzed using Spearman rank correlation coefficients. Cronbach $\alpha$ was calculated to test the internal consistency of both questionnaires. All statistical analyses were performed using the IBM SPSS Statistics, version 20.0.

Construct validity refers to the extent to which a test measures a particular concept such as a health-related patient-reported outcome measurement (HR-PROM). It was assessed by calculating the Spearman rank correlation coefficient to measure the degree of agreement between the FaCE and SAQ scores and the SF-12, FDI, eFACE, and HB scores. The correlation between the FaCE and SAQ scores was also assessed. Lower scores on the FaCE and SAQ questionnaires were assumed to be correlated to low eFACE and high $\mathrm{HB}$ scores, indicating severe facial function impairment. A Spearman rank correlation coefficient ( $r$ value) lower than 0.1 was interpreted in the present study as no correlation; a score between 0.1 and 0.3 , as a weak correlation; from 0.3 to 0.5 , as moderate; and $\geq 0.5$, as a strong correlation. ${ }^{25}$ 
The internal consistency of the Brazilian Portuguese version of the items of the FaCE and SAQ instruments was evaluated by calculating the Cronbach $\alpha$ coefficient. The internal consistency assesses homogeneity, that is, the extent to which items in an instrument are intercorrelated and if they measure the same concept (construct). ${ }^{26}$ A Cronbach $\alpha$ value of 0.8 is recommended; however, a value of 0.7 is considered satisfactory for each questionnaire unidimensional scale. ${ }^{21,27}$

\section{Results}

\section{Pilot Study}

Ten FP patients and ten individuals with normal facial function who were Brazilian Portuguese native speakers were enrolled in the pilot study. All normal individuals scored 100 (best) on the FaCE and 0 (no synkinesis) on the SAQ. The electronic survey and phone contacts showed no reports of difficulty in comprehension nor in answering the questionnaires. No adjustments were deemed necessary by the authors after the pilot study, and the final versions were approved for the validation study (which is available in the supplemental information section).

\section{Participants}

A total of 90 patients were prospectively included in the study and filled out the Brazilian Portuguese version of the FaCE, SAQ, FDI and SF-12. The population characteristics are shown in -Table 1. The total scores of the FaCE scale

Table 1 Description of the study cohort $(n=90)$

\begin{tabular}{|l|l|}
\hline Age, in years; median (IQR) & $44.5(28.8-62.0)$ \\
\hline Gender, $\boldsymbol{n}$ (\%) & \\
\hline Male & $36(40.0)$ \\
\hline Female & $54(60.0)$ \\
\hline Side, $\boldsymbol{n}$ (\%) & \\
\hline Left & $48(53.3)$ \\
\hline Right & $39(43.3)$ \\
\hline Bilateral & $3(3.3)$ \\
\hline $\begin{array}{l}\text { Duration of palsy, in days; } \\
\text { median (IQR) }\end{array}$ & $30.0(7.0-387.5)$ \\
\hline Previous treatment, $\boldsymbol{n}$ (\%) & \\
\hline Yes & $55(61.1)$ \\
\hline No & $35(38.8)$ \\
\hline Etiology, $\boldsymbol{n}$ (\%) & \\
\hline Bell palsy & $53(58.9)$ \\
\hline Trauma & $16(17.8)$ \\
\hline Ramsay Hunt syndrome & $5(5.6)$ \\
\hline Diabetes & $3(3.3)$ \\
\hline Acute otitis media & $3(3.3)$ \\
\hline Lyme disease & $2(2.2)$ \\
\hline Other & $8(8.9)$ \\
\hline
\end{tabular}

Abbreviation: IQR, interquartile range.
Table 2 Descriptive statistics of the scores of the FaCE scale and SAQ

\begin{tabular}{|l|l|l|l|l|}
\hline & Mean & SD & Median & Range \\
\hline FaCE scale & & & & \\
\hline Total & 40.9 & 22.9 & 38.3 & $3.3-96.7$ \\
\hline Facial movement & 28.0 & 29.3 & 16.7 & $0.0-100.0$ \\
\hline Facial comfort & 49.4 & 29.4 & 50.0 & $0.0-100.0$ \\
\hline Oral function & 40.2 & 37.1 & 25.0 & $0.0-100.0$ \\
\hline Eye comfort & 24.0 & 27.6 & 12.5 & $0.0-100.0$ \\
\hline Lacrimal control & 49.2 & 39.9 & 50.0 & $0.0-100.0$ \\
\hline Social function & 50.8 & 33.2 & 50.0 & $0.0-100.0$ \\
\hline SAQ & & & & \\
\hline Total & 34.5 & 15.6 & 30.0 & $20.0-84.4$ \\
\hline
\end{tabular}

Abbreviations: FaCE, Facial Clinimetric Evaluation; SAQ, Skynesis Assessment Questionnaire; SD, standard deviation.

ranged from 3.3 to 96.7 (mean: $40.9 \pm 22.9$ ), and the total SAQ score ranged from 20 to 84.4 (mean: $34.5 \pm 15.6$ ). The FaCE total and subscores and the SAQ total scores recorded at the clinical evaluation are summarized on -Table 2 .

\section{Reliability and Internal Validity}

The internal Consistency of the Brazilian Portuguese version of the items of the FaCE and SAQ instruments was tested by calculating the Cronbach $\alpha$ coefficient, as shown in - Table 3. The Cronbach $\alpha$ results were good for the total and domains scores of both instruments. The value of the Cronbach $\alpha$ for the total domain was of 0.881 for the FaCE, and of 0.809 for the SAQ.

Construct validity was demonstrated by determining the correlation between the total and subscores of the FaCE scale to the eFACE and HB, FDI and SF-12, by calculating the Spearman rank correlation coefficient. The same was done for the SAQ scores. The results are shown in - Table $\mathbf{4}$ and $\mathbf{5}$.

Good construct validity was achieved on the Brazilian Portuguese version of the FaCE scale. The total score of the FaCE had a strong correlation to that of the eFACE (-Fig. 2) and the HB score, with a Spearman $r$ value of 0.537 and $-0.538(p<0.001)$ respectively. The subscores had a strong correlation for facial movement to the eFACE total score (r: $0.649 ; p<0.001$ ), and a moderate correlation for oral function, eye comfort and social function ( $r$ : 0.452, 0.457 and 0.391 respectively; $p<0.001$ ). The same strength of correlation was found between the FaCE domain scores and the $\mathrm{HB}$ score. The Brazilian Portuguese SAQ also had good construct validity, with a moderate to strong correlation to the eFACE synkinesis subdomain ( $\mathrm{r}:-0.449 ; p<0.001)$. No correlation was found to the HB score ( - Table 4 ).

A moderate to strong correlation was found between the FaCE total score and the FDI and SF-12 scores $(p<0.004)$, and a weak correlation between FDI-S and the SAQ $(p=0.012)$ (-Table 5). The FaCE scale subdomains of facial comfort and lacrimal control showed a low to moderate and moderate (Spearman $r$ value of -0.260 and $-0.301 ; p=0.013$ and 0.004 respectively) to the SAQ total score. - Table 6. 
Table 3 Internal consistency of the FaCE scale and SAQ

\begin{tabular}{|l|l|l|}
\hline & Cronbach $\alpha$ & $95 \% \mathrm{Cl}$ \\
\hline FaCE scale & & \\
\hline Total & 0.881 & $0.842-0.914$ \\
\hline Facial movement & 0.811 & $0.732-0.870$ \\
\hline Facial comfort & 0.727 & $0.612-0.812$ \\
\hline Oral function & 0.846 & $0.766-0.898$ \\
\hline Eye comfort & 0.652 & $0.472-0.771$ \\
\hline Lacrimal control & $\mathrm{NA}^{*}$ & $\mathrm{NA}^{*}$ \\
\hline Social function & 0.843 & $0.783-0.890$ \\
\hline SAQ & & \\
\hline Total & 0.809 & $0.744-0.863$ \\
\hline
\end{tabular}

Abbreviations: $95 \% \mathrm{Cl}$, 95\% confidence interval; FaCE, Facial Clinimetric Evaluation; NA, not available; SAQ, Skynesis Assessment Questionnaire. Note: *Only one question in the subscale.
The validated translations of the FaCE and SAQ into Brazilian Portuguese are displayed in -supplemental appendices 1 and 2 respectively (Available online).

\section{Discussion}

In the present study, the FaCE scale and the SAQ were translated into Brazilian Portuguese and validated for clinical practice. Good psychometric properties were shown for both instruments. The internal validity of the FaCE and the SAQ were good. The Cronbach $\alpha$ results are in line with the values shown on the FaCE translation into Swedish, Dutch, German and Chinese. ${ }^{12-15}$ The original English version of the SAQ and, for instance, its Dutch translation, demonstrated Cronbach $\alpha$ values of 0.859 and 0.80 respectively, ${ }^{11,16}$ which is similar to the results of the present study.

The present study achieved good construct validity for the translation of both the FaCE and the SAQ.

Table 4 Correlation of the scores of the FaCE scale and SAQ to the scores of the HB and eFACE as expressed by the Spearman $\rho$ ( $p$-value)

\begin{tabular}{|c|c|c|c|c|c|}
\hline & HB & Total eFACE & eFACE static & eFACE dynamic & eFace synkinesis \\
\hline \multicolumn{6}{|l|}{ FaCE scale } \\
\hline Total & $-0.538(<\mathbf{0 . 0 0 1 )}$ & $0.537(<0.001)$ & $0.328(0.002)$ & $0.563(<0.001)$ & $-0.095(0.374)$ \\
\hline Facial movement & $-0.668(<\mathbf{0 . 0 0 1 )}$ & $0.649(<0.001)$ & $0.520(<0.001)$ & $0.712(<\mathbf{0 . 0 0 1 )}$ & $-0.293(0.005)$ \\
\hline Facial comfort & $-0.297(0.005)$ & $0.278(0.008)$ & $0.161(0.130)$ & $0.251(0.017)$ & $0.073(0.496)$ \\
\hline Oral function & $-0.470(<0.001)$ & $0.452(<0.001)$ & $0.399(<0.001)$ & $0.492(<\mathbf{0 . 0 0 1 )}$ & $-0.148(0.163)$ \\
\hline Eye comfort & $-0.463(<\mathbf{0 . 0 0 1 )}$ & $0.457(<0.001)$ & $0.319(0.002)$ & $0.451(<0.001)$ & $0.019(0.856)$ \\
\hline Lacrimal control & $0.083(0.435)$ & $-0.025(0.818)$ & $-0.081(0.450)$ & $-0.050(0.637)$ & $0.106(0.320)$ \\
\hline Social function & $-0.379(<\mathbf{0 . 0 0 1 )}$ & $0.391(<0.001)$ & $0.156(0.141)$ & $0.418(<\mathbf{0 . 0 0 1 )}$ & $-0.008(0.943)$ \\
\hline \multicolumn{6}{|l|}{ SAQ } \\
\hline Total & $-0.173(0.104)$ & $0.075(0.482)$ & $0.118(0.268)$ & $0.181(0.089)$ & $-0.449(<0.001)$ \\
\hline
\end{tabular}

Abbreviations: eFACE, Clinician-Graded Facial Function Scale; FaCE, Facial Clinimetric Evaluation; HB, House-Brackmann; SAQ, Skynesis Assessment Questionnaire.

Table 5 Correlation of the scores of the FaCE scale and SAQ to the scores of the FDI and SF-12 as expressed by Spearman $\rho$ ( $p$-value)

\begin{tabular}{|c|c|c|c|c|}
\hline & FDI-P & FDI-S & SF-12 PCS & SF-12 MCS \\
\hline \multicolumn{5}{|l|}{ FaCE scale } \\
\hline Total & $0.498(<0.001)$ & $0.567(<0.001)$ & $0.301(0.004)$ & $0.547(<0.001)$ \\
\hline Facial movement & $0.367(<0.001)$ & $0.138(0.195)$ & $0.164(0.122)$ & $0.181(0.088)$ \\
\hline Facial comfort & $0.332(0.001)$ & $0.494(<0.001)$ & $0.338(0.001)$ & $0.451(<0.001)$ \\
\hline Oral function & $0.423(<0.001)$ & $0.331(0.001)$ & $0.174(0.101)$ & $0.306(0.003)$ \\
\hline Eye comfort & $0.221(0.037)$ & $0.177(0.096)$ & $0.375(<0.001)$ & $0.181(0.087)$ \\
\hline Lacrimal control & $0.085(0.427)$ & $0.267(0.011)$ & $0.049(0.647)$ & $0.307(0.003)$ \\
\hline Social function & $0.401(<0.001)$ & $0.583(<0.001)$ & $0.205(0.052)$ & $0.570(<0.001)$ \\
\hline \multicolumn{5}{|l|}{ SAQ } \\
\hline Total & $-0.100(0.346)$ & $-0.263(0.012)$ & $-0.059(0.581)$ & $-0.084(0.432)$ \\
\hline
\end{tabular}

Abbreviations: FaCE, Facial Clinimetric Evaluation; FDI, Facial Disability Index; FDI-P, Facial Disability Index physical function; FDI-S, Facial Disability Index social/well-being function; MCS, mental health score; PCS, physical health score; SAQ, Skynesis Assessment Questionnaire; SF-12, Short-form 12. 


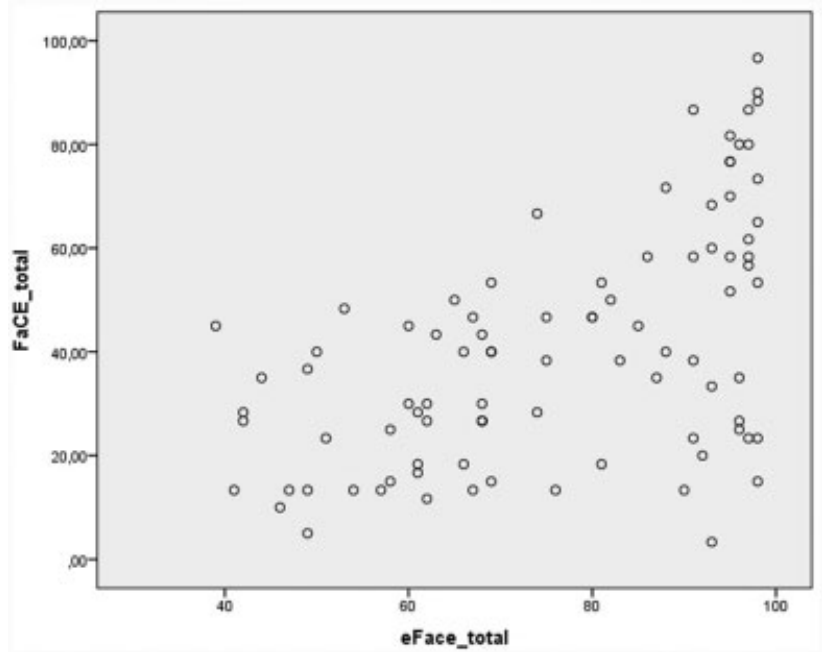

Fig. 2 Plot of the patients' total FaCE scale scores and eFACE total scores.

Table 6 Correlation of the scores of the FaCE scale and $\mathrm{SAQ}=$ as expressed by Spearman $\rho$ ( $p$-value)

\begin{tabular}{|l|l|}
\hline & SAQ Total score \\
\hline FaCE & \\
\hline Total & $-0.054(0.612)$ \\
\hline Facial movement & $0.158(0.138)$ \\
\hline Facial comfort & $-0.260(0.013)$ \\
\hline Oral function & $0.003(0.978)$ \\
\hline Eye comfort & $-0.003(0.977)$ \\
\hline Lacrimal control & $-0.301(0.004)$ \\
\hline Social function & $-0.070(0.510)$ \\
\hline
\end{tabular}

Abbreviation: FaCE, Facial Clinimetric Evaluation; SAQ, Skynesis Assessment Questionnaire.

The strength of the correlation between the Brazilian Portuguese FaCE scale and the eFACE, HB and FDI was strong, and between the Brazilian Portuguese SAQ and the eFACE synkinesis domain, it was moderate to high. Our strongest correlation was found between the FaCE facial movement domain and the eFACE dynamic score $(0.712 ; p<0.001)$.

Out of the correlations between the $\mathrm{HB}$ and $\mathrm{FaCE}$, the facial movement domain score demonstrated the highest $r$ value $(-0.668)$, which agrees with the result (r: -0.69) of the original FaCE scale validation performed by Kahn et al. ${ }^{10}$ This finding was similar in the Swedish, Dutch and German FaCE validations ( $r$ : $-0.81,-0.41$ and -0.686 respectively).

No correlation between the Brazilian Portuguese SAQ and the HB was found, and a weak correlation was demonstrated to the FDI-S ( $\mathrm{r}:-0.263 ; p=0.012$ ). The Dutch validation of the SAQ also reported the same findings ( $r:-0.320 ; p<0.05$ ). As expected, a higher correlation was found between the eFACE synkinesis score and the SAQ ( $\mathrm{r}$ : -0.449). The original SAQ validation performed by Mehta et $\mathrm{al}^{11}$ found a stronger correlation between the SAQ and the synkinesis Sunnybrook $^{6}$ scale scores (r: 0.769).
The correlation coefficient between the item and total FaCE scores and the FDI-P was of 0.498 , and to the SF-12 physical comfort score, it was of 0.301 . This was expected as the FDI is a disease-specific questionnaire for the $\mathrm{QoL}$ of the FP patient.

The association between disease-related impairment and QoL in patients with various disorders has been shown in a systematic review to be correlated to coefficients lower than $0.50 .^{28}$ This may explain the moderate to strong correlation found between the FaCE scale total score and the SF-12 scores, as well as other correlations found in the present study. The QoL scores mostly reflect the patient's perception about the consequences of the disease, depending on numerous additional, usually psychosocial, factors other than the disease itself. $^{29}$

\section{Strengths of the Present Study}

The translation, cross-cultural adaptation and validation of the FaCE and SAQ was performed following the recommendations for the translation of health-related questionnaires, with a thorough review of the steps by the committee of authors. $^{18-20,30}$ Content validity refers to the degree to which the content of an instrument is an adequate reflection of the construct to be measured. ${ }^{31}$ The US Food and Drug Administration (FDA) recommends content validity be established before evaluating other psychometric properties, which has been done in the present study. ${ }^{30}$ Good construct validity was achieved for the Brazilian Portuguese versions of the FaCE and SAQ. Internal consistency was also established, and the values found are consistent with the original English and translated versions.

\section{Limitations of the Present Study}

Responsiveness is defined as the ability of a questionnaire to detect clinically important changes over time and distinguish them from measurement errors. Responsiveness can be evaluated by calculating the area under the receiver operating characteristic (ROC) curve, which measures the ability of a questionnaire to distinguish patients who have changed from patients who have not, according to external criteria. ${ }^{21}$ Responsiveness could not be tested in the present study, limiting our interpretation of how scores on the scales being tested change in relation to the questionnaires answered by the patients in the present study over time. Responsiveness was also not tested in the original English version of the FaCE validation study, ${ }^{10}$ nor in its translation into other languages. ${ }^{12-15}$ The original English SAQ and its Dutch translation have not tested responsiveness either. ${ }^{11,16}$ In addition, the translated version of the FDI into Brazilian Portuguese used in the present study was not previously validated.

\section{Conclusion}

The Brazilian Portuguese versions of the FaCE and SAQ achieved high validity and reliability in the present study. These translated instruments were demonstrated to hold good psychometric properties, thus being suited for use in the clinical practice in Brazil and with Brazilian Portuguese 
speakers around the globe. These instruments provide clinicians with a patient-perceived QoL in the context of FP.

Conflicts of Interest

The authors have none to declare.

\section{References}

1 Ishii LE, Godoy A, Encarnacion CO, Byrne PJ, Boahene KD, Ishii M. What faces reveal: impaired affect display in facial paralysis. Laryngoscope 2011;121(06):1138-1143

2 Macgregor FC. Facial disfigurement: problems and management of social interaction and implications for mental health. Aesthetic Plast Surg 1990;14(04):249-257

3 Korb S, Wood A, Banks CA, Agoulnik D, Hadlock TA, Niedenthal PM. Asymmetry of Facial Mimicry and Emotion Perception in Patients With Unilateral Facial Paralysis. JAMA Facial Plast Surg 2016;18(03):222-227

4 Nellis JC, Ishii M, Byrne PJ, Boahene KDO, Dey JK, Ishii LE. Association Among Facial Paralysis, Depression, and Quality of Life in Facial Plastic Surgery Patients. JAMA Facial Plast Surg 2017; 19(03):190-196

5 House JW, Brackmann DE. Facial nerve grading system. Otolaryngol Head Neck Surg 1985;93(02):146-147

6 Ross BG, Fradet G, Nedzelski JM. Development of a sensitive clinical facial grading system. Otolaryngol Head Neck Surg 1996;114(03):380-386

7 Banks CA, Bhama PK, Park J, Hadlock CR, Hadlock TA. Cliniciangraded electronic facial paralysis assessment: the eFACE. Plast Reconstr Surg 2015;136(02):223e-230e

8 Ho AL, Scott AM, Klassen AF, Cano SJ, Pusic AL, Van Laeken N. Measuring quality of life and patient satisfaction in facial paralysis patients: a systematic review of patient-reported outcome measures. Plast Reconstr Surg 2012;130(01):91-99

9 VanSwearingen JM, Brach JS. The Facial Disability Index: reliability and validity of a disability assessment instrument for disorders of the facial neuromuscular system. Phys Ther 1996;76(12):1288-1298 , discussion 1298-1300

10 Kahn JB, Gliklich RE, Boyev KP, Stewart MG, Metson RB, McKenna MJ. Validation of a patient-graded instrument for facial nerve paralysis: the FaCE scale. Laryngoscope 2001;111(03):387-398

11 Mehta RP, WernickRobinson M, Hadlock TA. Validation of the Synkinesis Assessment Questionnaire. Laryngoscope 2007;117 (05):923-926

12 Marsk E, Hammarstedt-Nordenvall L, Engström M, Jonsson L, Hultcrantz M. Validation of a Swedish version of the Facial Disability Index (FDI) and the Facial Clinimetric Evaluation (FaCE) scale. Acta Otolaryngol 2013;133(06):662-669

13 Kleiss IJ, Beurskens CH, Stalmeier PF, Ingels KJ, Marres HA. Quality of life assessment in facial palsy: validation of the Dutch Facial Clinimetric Evaluation Scale. Eur Arch Otorhinolaryngol 2015;272 (08):2055-2061

14 Volk GF, Steigerwald F, Vitek P, Finkensieper M, Kreysa H, Guntinas-Lichius O. [Facial Disability Index and Facial Clinimetric Evaluation Scale: validation of the German versions]. Laryngorhinootologie 2015;94(03):163-168

15 Li Y, Jiang H, Wang K, et al. [Quality of life survey on patients with peripheral facial paralysis by using Chinese version of the FaCE scale]. Zhonghua Er Bi Yan Hou Tou Jing Wai Ke Za Zhi 2013;48 (01):11-16
16 Kleiss IJ, Beurskens CHG, Stalmeier PFM, Ingels KJAO, Marres HAM. Synkinesis assessment in facial palsy: validation of the Dutch Synkinesis Assessment Questionnaire. Acta Neurol Belg 2016;116(02):171-178

17 Wild D, Grove A, Martin M, et al; ISPOR Task Force for Translation and Cultural Adaptation. Principles of Good Practice for the Translation and Cultural Adaptation Process for Patient-Reported Outcomes (PRO) Measures: report of the ISPOR Task Force for Translation and Cultural Adaptation. Value Health 2005;8(02):94-104

18 Guillemin F, Bombardier C, Beaton D. Cross-cultural adaptation of health-related quality of life measures: literature review and proposed guidelines. JClin Epidemiol 1993;46(12):1417-1432

19 Acquadro C, Conway K, Hareendran A, Aaronson N; European Regulatory Issues and Quality of Life Assessment (ERIQA) Group. Literature review of methods to translate health-related quality of life questionnaires for use in multinational clinical trials. Value Health 2008;11(03):509-521

20 Maneesriwongul W, Dixon JK. Instrument translation process: a methods review. JAdv Nurs 2004;48(02):175-186

21 Mokkink LB, Terwee CB, Patrick DL, et al. The COSMIN checklist for assessing the methodological quality of studies on measurement properties of health status measurement instruments: an international Delphi study. Qual Life Res 2010;19(04):539-549

22 Harris PA, Taylor R, Thielke R, Payne J, Gonzalez N, Conde JG. Research electronic data capture (REDCap)-a metadata-driven methodology and workflow process for providing translational research informatics support. J Biomed Inform 2009;42(02):377-381

23 Silveira MF, Almeida JC, Freire RS, Haikal DS, Martins AEBL. Propriedades psicométricas do instrumento de avaliação da qualidade de vida: 12 -item health survey (SF-12). Cien Saude Colet 2013;18(07):1923-1931

24 Burholt V, Nash P. Short Form 36 (SF-36) Health Survey Questionnaire: normative data for Wales. JPublic Health (Oxf) 2011;33 (04):587-603

25 Hinkle DE, Wiersma W, Jurs SG. Applied Statistics for the Behavioral Sciences. 5th ed. Boston: Houghton Mifflin; 2003

26 Streiner DL. Starting at the beginning: an introduction to coefficient alpha and internal consistency. J Pers Assess 2003;80(01):99-103

27 Field A. Discovering statistics using SPSS. $3^{\text {rd }}$ Edition. London: SAGE Publications Ltd; 2009

28 Weisscher N, de Haan RJ, Vermeulen M. The impact of diseaserelated impairments on disability and health-related quality of life: a systematic review. BMC Med Res Methodol 2007;7:24

29 Tavares-Brito J, van Veen MM, Dusseldorp JR, Bahmad F Jr, Hadlock TA. Facial Palsy-Specific Quality of Life in 920 Patients: Correlation With Clinician-Graded Severity and Predicting Factors. Laryngoscope 2019;129(01):100-104

30 FDA. Guidance for industry: patient-reported outcome measures: use in medical product development to support labeling claims. U.S. Department of Health and Human Services FDA Center for Drug Evaluation and Research, U.S. Department of Health and Human Services FDA Center for Biologics Evaluation and Research, U.S. Department of Health and Human Services FDA Center for Devices and Radiological Health. Food and Drug Administration December 2009:1-39. Available at: https:// www.fda.gov/downloads/drugs/gui dances/ucm193282.pdf. Accessed May 2, 2018.

31 Mokkink LB, Terwee CB, Patrick DL, et al. The COSMIN study reached international consensus on taxonomy, terminology, and definitions of measurement properties for health-related patientreported outcomes. JClin Epidemiol 2010;63(07):737-745 